RESEARCH REPORT

\title{
Utility of indices of gun availability in the community
}

\author{
Edmond D Shenassa, Constantine Daskalakis, Stephen L Buka
}

J Epidemiol Community Health 2006;60:44-49. doi: 10.1136/jech.2005.039149

See end of article for authors' affiliations .....................

Correspondence to: Dr E D Shenassa, Department of Community Health and Centers for Behavioral and Preventive Medicine, Brown Medical School, One Hoppin Street, Suite 500 ,

Providence, RI 02903, USA; Edmond_Shenassa@ Brown.edu

Accepted for publication 12 July 2005
Objective: To estimate the degree to which the proportion of homicides and suicides committed with a gun is associated with reported availability of firearms across Chicago neighbourhoods.

Methods: Data were collected as part of the Project on Human Development in Chicago Neighborhoods (PHDCN), a combined neighbourhood and individual level study of the city of Chicago. The study used data from 837 PHDCN participants between the ages of 17 and 22, residing in 170 different neighbourhoods. Gun availability was measured via participant reports on whether they had carried a gun and whether they perceived gun access to be easy in their community. Data on suicides and homicides were obtained from the Chicago Department of Health.

Results: A 10\% change in the proportion of homicides committed by a gun in a neighbourhood was associated with a $20 \%$ increase in both the odds of reported gun access and reported gun carrying $(p=0.002$ and 0.048 , respectively). The proportion of firearm related suicides was not associated with either of those self reported measures.

Conclusions: The proportion of firearm related homicides, but not the proportion of firearm related suicides, is a useful predictor of gun availability across small areas such as neighbourhoods.
$\mathrm{V}$ arious indices are used to predict community level availability of firearms. These include laws and regulations governing sales and use of firearms, such as the need for an application, ${ }^{1-4}$ and subscription rates to magazines for firearm enthusiasts, such as Guns and Ammo. ${ }^{35}$ The most commonly used indices of community level availability of firearms are the proportion of homicides and the proportion of suicides committed by firearms. ${ }^{35-8}$ These indices are often used as a composite, Cook's index, which is the average of the percentages of all suicides and all homicides committed with a firearm. ${ }^{9-11}$ Cook's index has also been used in modified formats; for instance, it has been modified to exclude suicides and homicides among particular age groups, ${ }^{7}$ and to include accidental deaths caused by the misuse of firearms. ${ }^{3}$

The utility of these indices depends partly on how determined a particular homicidal or suicidal person may be to obtain a firearm. If most of the persons inclined to use a gun try to do so irrespective of the general extent of gun availability in their neighbourhood, then these indices will not be very useful surrogates. However, most individuals' resolve to obtain and use a firearm is probably moderated by the ease of doing so in practice. The utility of the Cook index has been evaluated within larger areas such as states and counties, ${ }^{11}{ }^{12} 31$ but utility of the Cook index has never been evaluated within smaller areas, such as neighbourhoods. These smaller areas constitute individuals' immediate environment; thus, are probably the most relevant in terms of availability of firearms.

In this paper, we evaluate the utility of the proportion of firearm related homicides and proportion of firearm related suicides as proxies of neighbourhood level availability of firearms. These proportions are the most widely used, and arguably, the most coherent of the indices currently used in the literature. Unlike magazine subscriptions and firearm related laws, use of a firearm in a homicide or suicide clearly indicates the presence of a firearm at a particular time and place. In addition, unlike firearm related laws that apply to broad geographical or administrative areas, the proportion of firearm related homicides and suicides can be computed from readily available data that correspond to functionally meaningful units of analysis, such as neighbourhoods or block groups.

The gold standard for estimating prevalence of firearms would be a sufficiently large sample with either direct enumeration of guns or with accurate self reporting of gun ownership within a target area. In the absence of such information, we used as our "alloyed" standard community dwelling youth's report of their access to firearms as assessed in a community survey conducted as part of the Project on Human Development in Chicago Neighborhoods (PHDCN). In this paper, our aim is to estimate the degree to which the proportion of homicides or the proportion of suicides committed with firearms estimate neighbourhood level availability of guns as reported by youth residing in these neighbourhoods.

\section{METHODS}

PHDCN is a population based, multilevel study of Chicago neighbourhoods and their residents; it combines a neighbourhood level study of the entire city of Chicago with an investigation of 80 randomly selected neighbourhoods, and a longitudinal cohort. ${ }^{13}$ By applying a spatial definition of "neighbourhood" - a collection of people and institutions occupying a subsection of a larger community-all 847 census tracts in Chicago were combined to create 343 "neighbourhood clusters" (NCs). NCs were created to be internally homogeneous with respect to racial and ethnic mix, socioeconomic status, housing density, and family organisation. This process was guided by 1990 census data and knowledge of Chicago's neighbourhoods and their geographical boundaries, and was validated by random effects analysis of variance. ${ }^{14}$ Here, we refer to NCs as "neighbourhoods," keeping in mind that other operational definitions might also have been used; NCs are comparable to large census tracts.

\section{Study participants}

As part of PHDCN, a probability sample of 80 of the 343 neighbourhoods was selected to provide adequate representation of a cross section of Chicago's population, and a sample of their residents was first surveyed in 1995. Trained 


\begin{tabular}{|c|c|c|}
\hline & $\begin{array}{l}\text { Neighbourhoods } \\
\text { n (\%) }\end{array}$ & $\begin{array}{l}\text { Participants } \\
\text { n (\%) }\end{array}$ \\
\hline \multicolumn{3}{|l|}{ Age } \\
\hline $15-18$ & & $505(60)$ \\
\hline $19-22$ & & $332(40)$ \\
\hline \multicolumn{3}{|l|}{ Sex } \\
\hline Female & & $429(51)$ \\
\hline Male & & $408(49)$ \\
\hline \multicolumn{3}{|l|}{ Race/ethnicity } \\
\hline White (non-Hispanic) & & $134(16)$ \\
\hline African American & & $270(32)$ \\
\hline Hispanic & & $327(39)$ \\
\hline Other & & 106 (13) \\
\hline \multicolumn{3}{|c|}{ Racial/ethnic composition of neighbourhoods } \\
\hline Predominantly white & $37(22)$ & $168(20)$ \\
\hline Predominantly African American & $56(33)$ & $194(23)$ \\
\hline Predominantly Hispanic & $26(15)$ & $153(18)$ \\
\hline \multirow{2}{*}{\multicolumn{3}{|c|}{$\%$ Homicides in neighbourhood committed w/gun* }} \\
\hline & & \\
\hline $0-60$ & $44(26)$ & $224(27)$ \\
\hline $61-70$ & $33(20)$ & $156(19)$ \\
\hline $71-80$ & $47(28)$ & $234(28)$ \\
\hline$>80$ & $45(27)$ & $214(26)$ \\
\hline \multicolumn{3}{|c|}{$\%$ Suicides in neighbourhood committed w/gunt } \\
\hline $0-20$ & $37(22)$ & $184(22)$ \\
\hline $21-40$ & 57 (34) & $303(36)$ \\
\hline $41-60$ & $40(24)$ & $184(22)$ \\
\hline$>60$ & $34(20)$ & $164(20)$ \\
\hline
\end{tabular}

interviewers then assessed study participants during private sessions at the subjects' residence. A total of 132915 and 18 year old participants were enrolled during this first wave of data collection. The overall response rate was $76 \%$, ranging from $79 \%$ for Hispanics to $63 \%$ for Asian/Pacific Islanders. ${ }^{13}$ In this paper, we use information collected during the second wave of data collection, which took place about two years after the first wave, for the original 15 and 18 year old cohorts. During PHDCN's second wave of data collection (1997-2000), 884 of the original participants in these two cohorts were re-interviewed; 767 of those were still living in the same neighbourhood they resided in during the first wave of PHDCN.

\section{Suicide and homicide data}

Data on homicides and suicides were compiled from annual mortality data files maintained by the Chicago Department of Public Health. Firearm related homicides were classified according to the International Classification of Diseases, 9th revision, (ICD-9) external causes of injury codes 965.0, 965.2, 965.3, 965.4. ${ }^{15}$ Firearm related suicides were similarly identified by ICD-9 external causes of injury codes E955.0E955.4. Data from the years 1990 to 1998 were averaged to compute the proportion of firearm related homicides and suicides in each neighbourhood.

\section{Measures of firearm availability}

In the absence of an accurate census of the prevalence of firearms across various neighbourhoods, we used, as our "alloyed" standard, self reports by youth residents of the city of Chicago of gun carrying and the ease by which guns may be obtained. For gun carrying, each participant was asked if s/ he "ever carried a concealed gun anywhere" (yes/no). For ease of access, each participant was asked "how easy is it for teenagers in the neighbourhood to get a gun." This question was originally scored on a 5 point scale $(1=$ very easy, to $5=$ impossible) and was then dichotomised as easy ( 1 or 2 ) versus not easy ( 3 though 5 ).
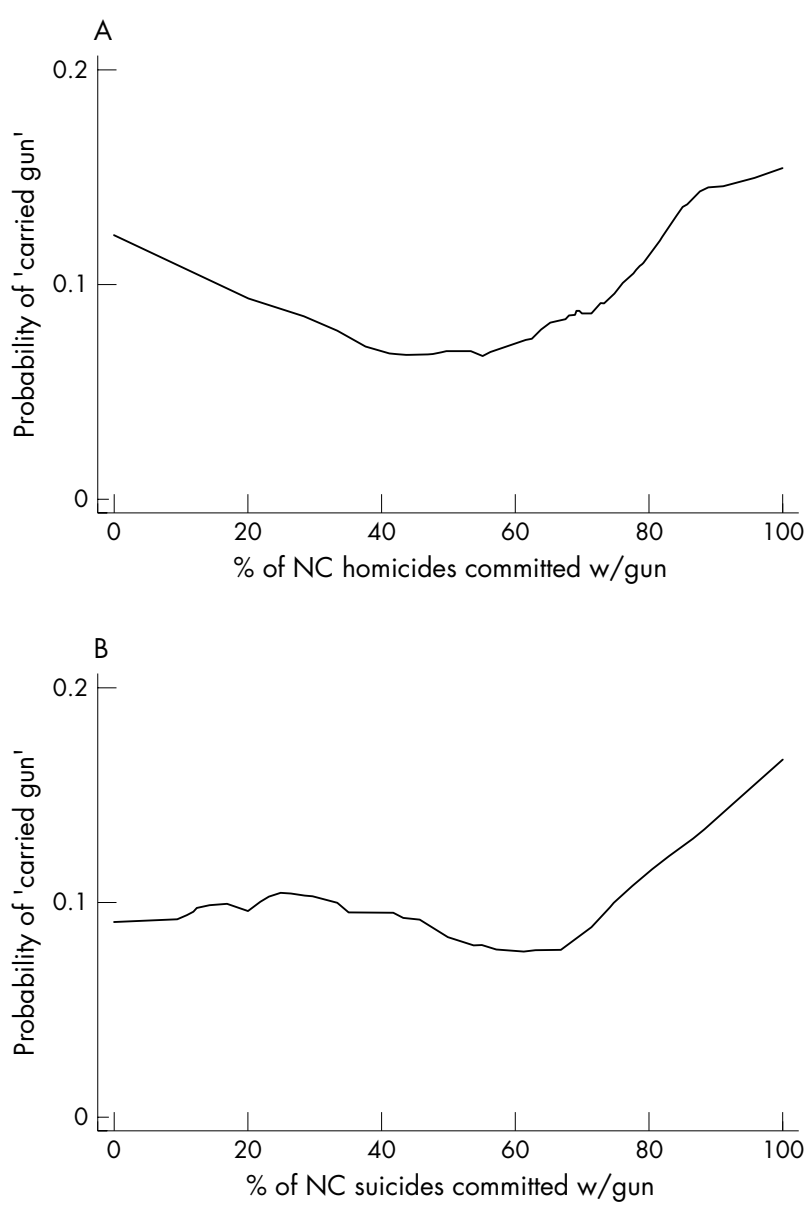

Figure 1 Lowess smoother for the proportion of participants reporting having carried a gun, as a function of: $(A)$ proportion of homicides in the neighbourhood committed with a gun, and (B) proportion of suicides in the neighbourhood committed with a gun. 
Table 2 Univariable results for reported gun carrying ("ever carried a gun") and perceived gun availability ("easy to get a gun")

\begin{tabular}{lllllll}
\hline & \multicolumn{2}{l}{ Ever carried a gun? } & & \multicolumn{2}{l}{ Easy to get a gun? } \\
\cline { 2 - 3 } & OR & $(95 \% \mathrm{Cl})$ & & OR & $(95 \% \mathrm{Cl})$ \\
\hline $\begin{array}{l}\text { \% Homicides committed w/gun }(10 \% \\
\text { increase) }\end{array}$ & 1.23 & $(1.06,1.44)$ & & 1.26 & $(1.10,1.44)$ \\
$\begin{array}{l}\text { Within neighbourhood correlation of } \\
\text { reports (clustering effect) }\end{array}$ & 0.79 & $(0.57,1.10)$ & 1.35 & $(1.02,1.80)$ \\
\hline
\end{tabular}

\section{Analytical approach}

Our reliance on self reports of gun availability, as our "alloyed" standard, raises the potential for misreporting. The probability of truthfully reporting on a sensitive topic, such as gun carrying is partly a function of respondents' perceptions of social desirability of that behaviour (see for example, Raghubir and Menon ${ }^{16}$ and Weeks and Moore. ${ }^{17}$ ) We do not have information on the study respondents' perceptions of social desirability of carrying guns. However, sociodemographic characteristics generally correlate reasonably well with perceptions of social desirability. ${ }^{16}{ }^{17}$ For example, we would expect men and older respondents to be more likely than women and younger respondents to find it acceptable to carry guns and to perceive guns to be more readily accessible. ${ }^{18}$ Therefore, we controlled for respondents' age, sex, and race/ethnicity.

Presumably, the association between proportions of firearm related homicides and suicides with self reports of gun carrying is influenced by other neighbourhood level correlates of violent behaviour, such as a neighbourhood's level of social cohesion. ${ }^{19-22}$ However, our aim was not to identify or control for such potential mediators of the link between proportions of firearm related homicides and suicides and self reports of gun availability (see Molnar et al $^{23}$ for a study of neighbourhood level determinants of gun carrying). Rather, our aim was to estimate the strength of this link. For this reason, we are not including in our analyses neighbourhood level variables. A similar logic can also apply to individual level variables. Neighbourhood rates of gun availability vary, in part, as a function of residents' demographics. Controlling for these variables might amount to over controlling, hence, diluting the utility of the proportion of homicides and suicides committed with firearms.

Consequently, we fit two logistic regression models, one with and one without age, sex, and race/ethnicity included in the analytic model. The multivariable model with these three demographic variables was fitted to control for potential reporting bias.

To account for the expected clustering of outcomes by neighbourhood, we used a generalised estimating equations (GEE) approach. GEEs typically use the correlation coefficient to quantify the correlation between outcomes. However, we used the alternating logistic regression method, a GEE variation that uses the odds ratio instead of the correlation coefficient, as the former is a more appropriate measure of association between dichotomous outcomes. ${ }^{24}$ We computed all confidence intervals and $\mathrm{p}$ values using the robust ("sandwich") variance estimator. All analyses were carried out in SAS 8.2 (SAS Institute, Cary, NC).

\section{RESULTS}

The analyses were based on data from 835 second wave PHDCN residing in 170 different neighbourhoods. Compared with respondents from the first wave of PHDCN who were lost to follow up, the 835 respondents in the analytical sample were slightly more likely to be Hispanic (36\% v 39\%), less likely to be black ( $38 \% v 32 \%)$, and less likely to be white $(17 \% \vee 16 \%)$. The two groups did not differ on an index of socioeconomic status that reflects both education and income. The number of study participants per neighbourhood ranged from 1 to 27 , with a median of 2 (mean $=4.9$, standard deviation $=5.2$ ). Table 1 presents a descriptive summary of the study's neighbourhoods and their residents.

As designed, most neighbourhoods were comparatively homogeneous with respect to racial/ethnic composition. According to 1990 census data, among 37 neighbourhoods $(22 \%)$ two thirds or more of the residents were white, while 56 neighbourhoods (33\%) were predominantly black, 26 neighbourhoods $(15 \%)$ were predominantly Hispanic, and the remaining 51 (30\%) had a mixed racial composition. According to 1990-98 Chicago Department of Public Health data, there were 4176 homicides reported among 169

Table 3 Multivariable results for reported gun carrying ("ever carried a gun") and perceived gun availability ("easy to get a gun")

\begin{tabular}{|c|c|c|c|c|c|c|}
\hline & \multicolumn{3}{|c|}{ Ever carried a gun? } & \multicolumn{3}{|c|}{ Easy to get a gun? } \\
\hline & $\%$ & OR & $(95 \% \mathrm{Cl})$ & $\%$ & OR & $(95 \%$ Cl) \\
\hline \multicolumn{7}{|l|}{ Age } \\
\hline $15-18$ & 7.2 & 1.00 & Ref & 73.7 & 1.00 & \\
\hline $19-22$ & 13.6 & 2.06 & $(1.28,3.31)$ & 68.7 & 0.81 & $(0.50,1.12)$ \\
\hline \multicolumn{7}{|l|}{ Sex } \\
\hline Female & 2.6 & 1.00 & Ref & 75.7 & 1.00 & \\
\hline Male & 17.2 & 8.10 & $(4.21,15.58)$ & 67.7 & 0.68 & $(0.50,0.93)$ \\
\hline \multicolumn{7}{|l|}{ Race/ethnicity } \\
\hline white (non-Hispanic) & 4.5 & 1.00 & Ref & 53.0 & 1.00 & Ref \\
\hline African American & 13.3 & 2.80 & $(1.12,7.03)$ & 81.3 & 2.93 & $(1.76,4.88)$ \\
\hline Hispanic & 8.0 & 1.78 & $(0.73,4.34)$ & 72.7 & 1.80 & $(1.12,2.92)$ \\
\hline Other & 12.3 & 2.00 & $(0.64,6.21)$ & 66.3 & 1.51 & $(0.84,2.69)$ \\
\hline$\%$ Homicides committed w/gun ( $10 \%$ increase) & & 1.21 & $(1.00,1.46)$ & & 1.21 & $(1.07,1.37)$ \\
\hline $\begin{array}{l}\text { Within neighbourhood correlation of reports (clustering } \\
\text { effect) }\end{array}$ & & 0.91 & $(0.61,1.35)$ & & 1.21 & $(0.99,1.47)$ \\
\hline
\end{tabular}



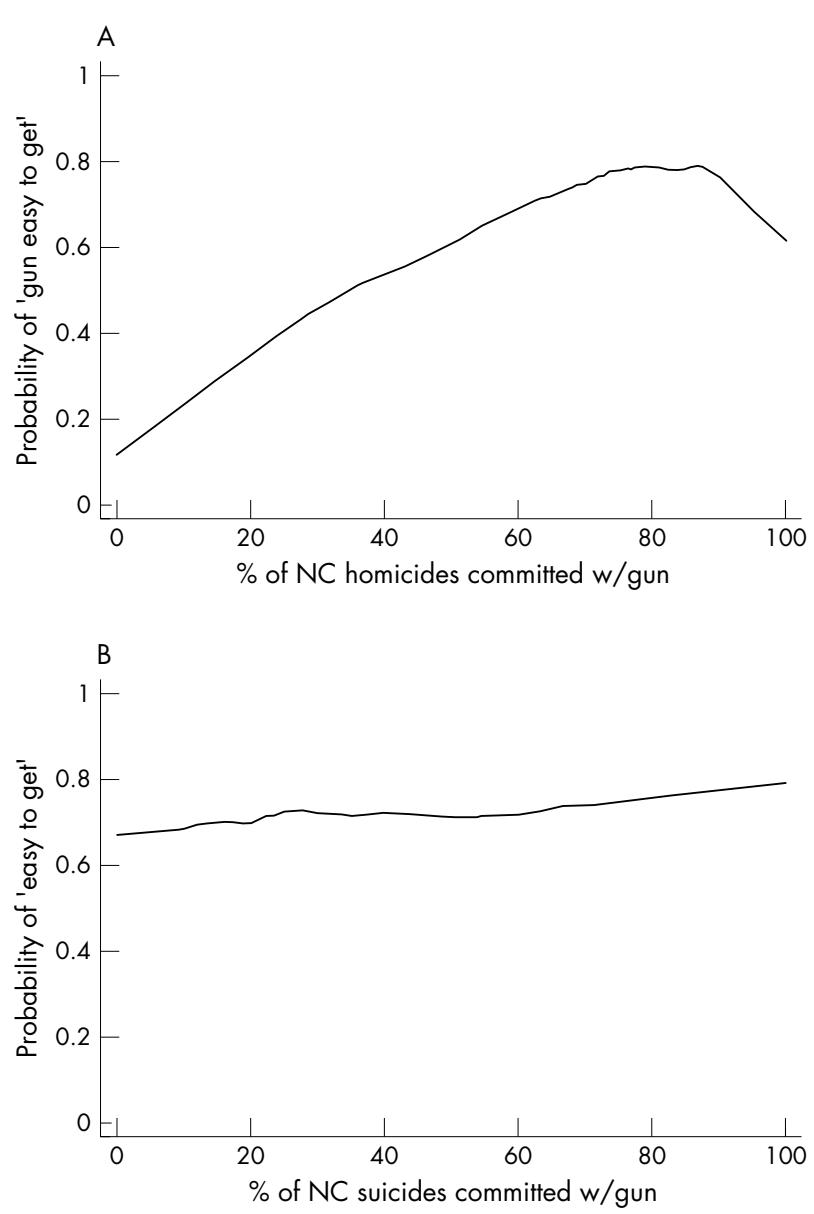

Figure 2 Lowess smoother for the proportion of subjects reporting that a gun is easy to get in the neighbourhood, as a function of: (A) proportion of homicides in the neighbourhood committed with a gun, and (B) proportion of suicides in the neighbourhood committed with a gun.

neighbourhoods (range $=1-84$, median $=17$ ), with 3053 $(73 \%)$ of those committed with a firearm. The proportion of a neighbourhood's homicides committed with a gun ranged from $0 \%$ to $100 \%$, with a median of $73 \%$. In addition, during the same time period, there were 1174 suicides reported among 168 neighbourhoods (range $=1-26$, median $=6$ ); of those suicides, $460(39 \%)$ were committed with a firearm. The proportion of a neighbourhood's suicides committed with a gun ranged from 0 to $100 \%$ (median $=38 \%$ ).

The study participants were between 15 and 22 years of age, with a median of 17 (mean $=17.9$, standard deviation $=1.7$ ). Their age distribution was essentially bimodal, with most subjects being $16-17$ or 19-20 years old per design.

\section{Gun carrying}

Overall, $81(10 \%)$ participants reported ever having carried a gun (two participants did not answer this question). Figure 1 shows a non-parametric smoother of the probability of gun carrying as a function of the proportion of homicides and of suicides committed with a gun. Proportion of participants reporting having carried a gun, as a function of: (A) proportion of homicides in the neighbourhood committed with a gun, and (B) proportion of suicides in the neighbourhood committed with a gun. The proportion of firearm related homicides appeared to have a $\mathrm{U}$ shaped distribution. However, further investigation showed that there were few observations at the low end of the range ( 44 participants in
13 neighbourhoods, in which the proportion of firearm related homicides was less than $40 \%$ ) and that a monotone trend fit most of the data well. Similarly, for the proportion of firearm related suicides, the data were sparse at the high end and the overall distribution appeared quite flat in the main body of the data.

The unadjusted odds (table 2) for gun carrying changed by $23 \%$ for every $10 \%$ change in the proportion of homicides in the neighbourhood that were committed by a gun $(p=0.008)$. These results were essentially unchanged in the multivariable model (table 3 ). The adjusted odds of gun carrying changed by $21 \%$ for every $10 \%$ change in the proportion of homicides in the neighbourhood that were committed by a gun $(p=0.048)$. In addition, the odds of gun carrying for older adolescents were twice that of their younger counterparts $(\mathrm{p}=0.003)$, and men were eight times more likely to report ever carrying a gun than women $(p<0.001)$. Minorities tended to provide more frequent reports of gun carrying than white people, but the differences across racial/ethnic groups were not significant $(p=0.126)$. There was no significant clustering of reports of gun carrying within neighbourhoods (odds ratio $=0.91, p=0.62$ ). In parallel multivariable analyses, the proportion of firearm related suicides was not associated with gun carrying (adjusted odds ratio for a $10 \%$ increase in gun related suicides $=1.01,95 \% \mathrm{CI}=0.92$ to $1.11, \mathrm{p}=0.85$, results not shown).

\section{Gun availability}

Overall, 559 of 779 subjects (72\%) felt it was easy to obtain a gun in their neighbourhood ( 58 subjects did not answer this question). Figure 2 shows a non-parametric smoother of the probability of perceived gun availability as a function of the proportion of homicides and of suicides committed with a gun. As with gun carrying, the curve for homicides appears much steeper than the curve for suicides.

Table 2 presents the univariable GEE model for the gun availability that included the proportion of firearm related homicides. The unadjusted odds for gun availability changed by $26 \%$ for every $10 \%$ change in the proportion of homicides in the neighbourhood that were committed by a gun $(\mathrm{p}=0.001)$. As with reported gun carrying, results from the univariable model remained essentially unchanged after adjustment for age, sex, and race/ethnicity (table 3). Perceived ease of obtaining a gun was positively associated with the proportion of the neighbourhood's homicides that were committed with a gun $(p=0.002)$. However, in contrast with the reported gun carrying, older and younger adolescents did not differ much in their perceptions regarding gun availability $(p=0.196)$ and women were significantly more likely than men to report that a gun was easy to obtain in their community $(p=0.015)$. The race/ethnicity reporting on gun availability paralleled that for gun carrying, with minority participants being more likely to report that guns were easy to obtain $(p=0.007)$. The gun availability perceptions of participants from the same neighbourhood were weakly correlated (odds ratio $=1.21$, p=0.056). Finally, as with gun carrying, the proportion of firearm related suicides was not associated with predictor of gun availability in the neighbourhood (adjusted odds ratio for a

What this paper adds

This is the first neighbourhood level study of the utility of the proportion of firearm related homicides and proportion of firearm related suicides in predicting community level availability of firearms. 


\section{Policy implications}

Easy access and availability of firearms is an important public health problem. It has been argued that reducing the number of available firearms, either through safer storage practices or legislation limiting sales, can potentially reduce the number of successful suicide attempts by forcing those contemplating suicides to use less lethal methods and by reducing the number of impulsive suicide acts. Studies of these issues, as well as the planning of public health programmes, can benefit from the accurate estimates of availability of firearms. Because direct estimates are difficult to obtain, indirect estimates through surrogate indices need to be evaluated. This study considers the utility of indices that can be computed from readily available neighbourhood level data. Consequently, impact of firearm related policy can be considered at a functionally meaningful level, rather than at larger less meaningful geographical areas as is currently the case.

$10 \%$ difference $=1.04,95 \% \mathrm{CI}=0.96$ to $1.11, \mathrm{p}=0.34$, results not shown).

\section{DISCUSSION}

We estimated the degree to which the proportion of firearm related homicides and the proportion of firearm related suicides are associated with availability of firearms across Chicago neighbourhoods. As a gold standard of gun availability is unavailable, we used reports of Chicago residents on two questions regarding gun availability as our alloyed standard: "ever carried a concealed gun anywhere", and "how easy is it for a teenager in the neighbourhood to get a gun". Analysis with or without control for potential differential reporting by age, sex, and race/ethnicity yielded very similar results.

The proportion of a neighbourhood's homicides committed with firearms correlated to the same extent with both self reported gun carrying and perceived ease of access to guns in the neighbourhood. In contrast, the neighbourhood's proportion of suicides committed with firearms did not correlate with either of these self reported measures. This latter finding was surprising as we anticipated comparable utility for the two indices. The lack of association between proportion of suicides committed by a gun and the participants' self reports may be partly attributable to the comparatively smaller number of suicides compared with homicides (1174 $v 4176$ ). However, the computed confidence limits exclude any substantial association between firearm related suicides and either gun carrying or perceived ease of access to guns. This absence of association contradicts a robust association reported by Azarel et al, ${ }^{12}$ although those findings were based on state level data.

Our findings must be considered in light of the study's strengths and limitations. Because of insufficient sample size, it is not possible with these data to rank neighbourhoods in terms of their gun prevalences. Even though the number of study participants from each individual neighbourhood was small, the total study sample was substantial. In addition, the study is unique in that its participants were selected to be representative of the entire Chicago population and to reflect the socioeconomic, racial, and ethnic diversity of its neighbourhoods.

The assessment of gun availability in each community was based on self reports of the study participants. Because of the small number of participants from each neighbourhood, it is probable that gun availability was estimated with a degree of error for some communities. This misclassification of the outcome was most probably random and would be expected to generally bias the results towards the null. On the other hand, the estimated proportions of homicides or suicides committed with a gun within each neighbourhood should be comparatively more accurate, as they were computed as averages of population data over nine consecutive years.

We also note that our survey inquired about an illegal activity, Chicago bans handguns and federal law prohibits handgun possession by minors. However, there is a long and rich history of survey research on illegal behaviours, such as substance use, as well as gun use and ownership. Also, the good rapport established with respondents probably increased likelihood of accurate reporting. Nevertheless, it would be useful to discover if the same findings would be replicated among older populations.

Easy access and availability of firearms is an important public health problem. ${ }^{25-29}$ It has been argued that reducing the number of available firearms, either through safer storage practices or legislation limiting sales, can potentially reduce the number of successful suicide attempts by forcing those contemplating suicides to use less lethal methods $\mathrm{s}^{28}$ and by reducing the number of impulsive suicide acts. ${ }^{29}$ Studies of these issues, as well as the planning of public health programmes, can benefit from accurate estimates of availability of firearms. ${ }^{30}$ Because direct estimates are difficult to obtain, indirect estimates through surrogate indices need to be evaluated. In this study, we have shown that one of these indices, the proportion of homicides committed with a gun, shows significant association with self reported measures of gun availability and merits further evaluation.

\section{Authors' affiliations}

E D Shenassa, Department of Community Health, Brown School of Medicine, Providence, USA and Centers for Behavioral and Preventive Medicine, Brown School of Medicine and The Miriam Hospital, USA C Daskalakis, Biostatistics Section, Department of Medicine, Thomas Jefferson University, USA

S L Buka, Departments of Society, Human Development and Health, Harvard School of Public Health, and Epidemiology, Harvard School of Public Health, USA

Funding for PHDCN was provided by the John D and Catherine T MacArthur Foundation, the National Institute of Mental Health, and National Institute of Justice.

Conflicts of interest: none declared.

\section{REFERENCES}

1 Boor M, Bair JH. Suicide rates, handgun control laws, and sociodemographic variables. Psychol Rep 1990;66:923-30.

2 Sloan JH, Rivara FP, Reay DT, et al. Firearm regulations and rates of suicide. A comparison of two metropolitan areas. N Engl J Med 1990;322:369-73.

3 Lester D. Firearm availability and the incidence of suicide and homicide. Acta Psychiatr Belg 1988;88:387-93.

4 Lester D. Research note: gun control, gun ownership, and suicide prevention. Suicide Life Threat Behav 1988;18:176-80.

5 Lester D. Gun ownership and suicide in the United States. Psychol Med 1989;19:519-21

6 Kennedy BP, Kawachi I, Prothrow-Stith D, et al. Social capital, income inequality, and firearm violent crime. In: Kawachi I, Kennedy BP, Wilkinson RC, eds. The society and population health reader: income inequality and health. New York, NY: The New Press, 1999.

7 Miller M, Azrael D, Hemenway D. Firearm availability and unintentional firearm deaths, suicide, and homicide among 5-14 year olds. J Trauma 2002; 52:267-75.

8 Lester D. The availability of firearms and the use of firearms for suicide: a study of 20 countries. Acta Psychiatr Scand 1990;81:146-7.

9 Hemenway D, Kennedy BP, Kawachi I, et al. Firearm prevalence and social capital. Ann Epidemiol 2001;11:484-90.

10 Miller M, Azrael D, Hemenway D. Firearm availability and unintentional firearm deaths. Accid Anal Prev 2001;33:477-84.

11 Cook P. The effect of gun availability on robbery and robber murder: a cross sectional study of 50 cities. Policy Study Review Annual 1979;3:743-81.

12 Azrael D, Cook P, Miller M. State and local prevalence of firearms ownership: measurement, structure, and trends. National Bureau of Economic Research, working paper 8570, 2001 (http://www.nber.org/papers/w8570). 
13 Earls F, Buka SL. Project on Human Development in Chicago neighborhoods. Washington, DC: National Institute of Justice, 1997.

14 Raudenbush S, Buka S. Sampling Plan. National Institute of Justice Research Report: Project on Human Development in Chicago Neighborhoods, 1997.

15 World Health Organisation. International classification of diseases, 9th revision. Geneva: WHO, 1980.

16 Raghubir P, Menon G. Asking sensitive questions: the effects of type of referent and frequency wording in counterbiasing methods. Psychology and Marketing 1996;13:633-52.

17 Weeks M, Moore R. Ethnicity of interviewer effects on ethnic respondents. Public Opinion Quarterly 1981;45:245-9.

18 Ludwig J, Cook PJ, Smith TW. The gender gap in reporting household gun ownership. Am J Public Health 1998;88:1715-18.

19 Sampson R, Raudenbush S, Earls F. Neighborhoods and violent crime: a multilevel study of collective efficacy. Science 1997;277:918-24.

20 Shenassa E, Catlin S, Buka S. Gun availability, psychopathology, and risk of death from suicide attempt by gun. Poster presented at the meeting of American College of Epidemiology, Atlanta, GA, 2000. Ann Epidemiol 2000;10:482.

21 Morenoff JD, Sampson RJ, Raudenbush SW. Neighborhood inequality, collective efficacy, and the spatial dynamics of urban violence. Criminology 2001;39:517-59.

22 Sampson RJ, Morenoff JD, Earls F. Beyond social capital: spatial dynamics of collective efficacy for children. American Sociological Review 1999;64:633-60.
23 Molnar BE, Miller MJ, Azrael D, et al. Neighborhood predictors of concealed firearm carrying among children and adolescents. Arch Pediatr Adolesc 2004; 158:657-64

24 Carey VC, Zeger SL, Diggle PJ. Modelling multivariate binary data with alternating logistic regressions. Biometrika 1993;80:517-26.

25 United Nations. Report to the Secretary General of the United Nations by the Economic and Social Council, Commission on Crime Prevention and Criminal Justice. 25 Apr 1997, E/CN. 15/1997/4

26 Blendon RJ, Young JT, Hemenway D. The American public and the gun control debate. JAMA 1996;275:1719-22

27 Hemenway D, Solnick SJ, Azrael DR. Firearm training and storage. JAMA 1995;273:46-50.

28 Shenassa E, Catlin S, Buka S. Lethality of firearms relative to other suicide methods: a population based study. J Epidemiol Community Health 2003;57:120-4.

29 Shenassa E, Rogers M, Spalding K, et al. Safer storage of firearms at home and risk of suicide: a study of protective factors in a nationally representative sample. J Epidemiol Community Health 2004;58:841-8.

30 Shenassa E. Delivering the goods: the relevance of classification accuracy to the design of community intervention and prevention programs. Journal of Community Psychology 2002;30:197-210.

31 Stolzenberg L, D'Alessio S. Gun availability and violent crime: new evidence from national incident-based reporting system. Social Forces 2000;78:1461-82. 